\title{
Reflective Thermochromic Display on Polyethylene Naphthalate Film
}

\author{
Kyong Chan Heo ${ }^{1}$, Phil Kook Son ${ }^{2}$, Youngku Sohn ${ }^{3}$, Jonghoon $\mathbf{Y i}^{1}$, \\ Jin Hyuk Kwon", and Jin Seog Gwag ${ }^{1 *}$ \\ ${ }^{1}$ Department of Physics, Yeungnam University, 214-1 Dae-dong, Gyeongsan 712-749, Korea \\ ${ }^{2}$ Electronics and Regional Innovation Center-component and Materials for Information Display, \\ Kyung Hee University, Yongin 446-701, Korea \\ ${ }^{3}$ Department of Chemistry, Yeungnam University, 214-1 Dae-dong, Gyeongsan 712-749, Korea
}

(Received October 29, 2012 : revised January 14, 2013 : accepted January 30, 2013)

\begin{abstract}
A reflective flexible display was fabricated by placing a thermochromic pigment on a polyethylene naphthalate (PEN) substrate coated with an indium tin oxide (ITO) film, and its thermo-optical characteristics were investigated. The reflective thermochromic display showed good image quality with a reflectance of approximately $65 \%$. As a flexible display, the display showed reliability without damage to the image even after the display was bent strongly. The reflective display cell exhibits continuously the gray level according to the temperature controlled by applied voltage. This low cost display is expected be used in outdoor poster applications where information needs to be presented clearly.
\end{abstract}

Keywords : Thermochromic display, Thermochromic pigment, Flexible display, Reflective display OCIS codes : (120.2040) Displays; (160.6840) Thermo-optical materials; (130.0250) Optoelectronics

\section{INTRODUCTION}

Reflective flexible displays have attracted considerable attention as a next generation display because of their lightweight, rolling or folding capability for 3D configurations, low power consumption and sunlight readability. These merits highlight potential future applications, such as paper-like displays, smart cards and watches as well as wearable displays and actuators, etc.

A few types of flexible displays using liquid crystal, electrophorectic materials, or organic light emitting materials have been studied. Among them, reflective liquid crystals (LCDs) [1-3] and electrophorectic displays (EPD) [4] have been studied for mobile devices, outdoor signboard applications and e-books. Although the technologies of conventional displays, such as LCDs, are relatively well established for flexible displays, most are expensive and the manufacturing process is too complex for flexible display applications and outdoor displays. On the other hand, reflective thermochromic displays have a much simpler fabrication process compared to conventional electron devices.

Thermochromic displays have been explored and manufactured for application to emerging devices using chromatic materials, such as electronic papers. Owing to the range of brightness and optical properties that respond to external stimuli, such as heat, mechanical stress and ligand interactions, thermochromic materials have been studied widely in biochemical, chemical, and other applied research areas [5-9]. The applications for such materials include thermochromic displays, color filters and temperature sensors $[10,11]$.

Recently, L. Liu et al. [5] reported a thermally-actuated display fabricated from monochromatic thermochromic polymer and silver polydimethelysiloxane (PDMS) conductive wiring patterns. The thermochromic powder turns from a dark state to a white state above $60^{\circ} \mathrm{C}$. O. Yarimaga et. al. reported a thermochromic display based on thermochromic conjugated polydiaceltylenes superamolecules [8]. Unfortunately, the thermochromic polymer materials were activated at $180^{\circ} \mathrm{C}$, which is too high for use as a display requiring a rapid response time, low power consumption and safety. For the case of the fabrication, design and optimization of the thermooptical properties of a thermally-actuated display, color reversibility according to temperature and the color transition temperature of thermochromic materials must be considered in conjunction [5-7]. The monochromatic thermochromic pigment reported in this paper generates a color transition

\footnotetext{
*Corresponding author: sweat3000@ynu.ac.kr

Color versions of one or more of the figures in this paper are available online.
} 
at $38^{\circ} \mathrm{C}$, which is an appropriate temperature for low power consumption in the transition of brightness.

This paper reports a reflective flexible display fabricated using thermochromic pigment on polyethylene naphthalate (PEN) substrates coated with an indium tin oxide (ITO) film. This display can be adapted easily to a range of application environments. In addition, the manufacturing process is quite simple and relatively inexpensive. The thermo-optical properties of the thermochromic display were also investigated.

\section{EXPERIMENTS}

The monochromatic thermochromic pigment was obtained from H.W SANDS. CO. The pigment was composed of microcapsules that change the brightness reversibly. The transition temperature of the pigment, ranging from $-10^{\circ} \mathrm{C}$ to $69^{\circ} \mathrm{C}$, can be tailored by adjusting the pigment compositions [12]. For commercial reasons, the precise chemical compositions of the thermochromic pigment purchased from H.W SANDS CORP. are proprietary information but are believed to be similar to other formulations reported in the literature $[13,14]$.

In this study, a thermochromic display was simply manufactured with approximately $50 \mu \mathrm{m}$ thickness of monochromatic thermochromic pigment coated on the patterning indium tin oxide (ITO) sputtered on polyethylene naphthalate (PEN) film. The ITO-heaters were designed roughly to be $0.2 \times 0.2 \mathrm{~cm}^{2}$ with $0.5 \mathrm{~mm}$ between adjacent pixels. The spacing creates heat isolation among the cells. The thermochromic pigment, whose color is black at room temperature and changes to white at approximately $38^{\circ} \mathrm{C}$, was employed. As observed by scanning electron microscopy (SEM, Fig. 1(a)), $97 \%$ of the microcapsulated thermochromic pigment particles were less than $6 \mu \mathrm{m}$ in size.

The thermochromic display cell was fabricated as follows. Indium tin oxide (ITO, $90 \mathrm{wt} \% \mathrm{In}_{2} \mathrm{O}_{3}$ and $10 \mathrm{wt} \% \mathrm{SnO}_{2}$ ) films were deposited on PEN substrates by RF magnetron sputtering. Briefly, all substrates were cleaned ultrasonically with ethanol and deionized water, and dried on a hot plate at $100^{\circ} \mathrm{C}$ for 5 minutes. Deposition was performed in 20 sccm of flowing $\mathrm{Ar}$ gas controlled by a mass flow-meter. The working and base pressure of the sputtering system was $8 \times 10^{-4}$ Torr and $5 \times 10^{-6}$ Torr, respectively. The applied RF power throughout ITO deposition was $15 \mathrm{~W}$. Deposition was carried out at $100^{\circ} \mathrm{C}$ for 40 minutes. The thickness of the ITO film is roughly $80 \mathrm{~nm}$. The electrical resistivity of the ITO-sputtered PEN film was approximately $2.55 \times 10^{-2} \Omega \cdot \mathrm{cm}$. Because the heating material is an ITO conductor with the appropriate resistance, the temperature is tunable by adjusting the electrical current. The thermochromic pigment was deposited on the ITO heater by a spray method. Fig. 1(b) presents the fabricated thermochromic display cell. The spectral reflectance was measured as a function of the applied voltage using a Cary 5000 UV-VIS-NIR spectrophotometer (Agilent-Korea).

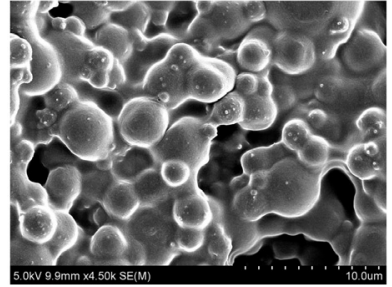

(a)

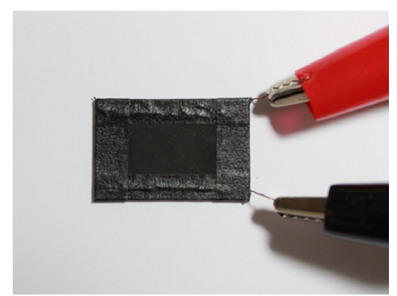

(b)
FIG. 1. (a) SEM image of the thermochromic pigment coated on a glass, (b) fabricated unit thermochromic display cell.

\section{RESULTS AND DISCUSSION}

The chromism of the reflective thermochromic display (RTD) cell was examined as a function of the supplied power that can drive the current in the cell. This generates brightness due to a change in temperature. The temperature could be controlled by adjusting the intensity of the driving voltage. The measurements were performed at room temperature $\left(24^{\circ} \mathrm{C}\right)$. The display cell was fabricated on a $1.5 \times 2.5 \mathrm{~cm}^{2}$ ITO-sputtered PEN film. The temperature was reading at a steady state using a thermometer with a thermocouple probe attached to the center of the display cell.

Figure 2 shows temperature of the active pixel according to voltage, average turn on/off times during repetitive voltage cycles, and pixel images of the RTD cell when the applied voltages were changed from $0 \mathrm{~V}\left(24^{\circ} \mathrm{C}\right)$ to $8 \mathrm{~V}$ $\left(72^{\circ} \mathrm{C}\right)$. As shown in Fig. 2(a), the temperature of the thermochromic cell increased roughly as a square function of applied voltage. In addition, the display cell showed a reliability without significant change in repetitive turn-on/off as a crucial factor for the performance display as shown in Fig. 2(b). In Fig. 2(b), turn on time was measured by the time necessary for the display to become from the dark state at room temperature to the white state (at $43^{\circ} \mathrm{C}$ ). In case of turn off time, we measured the time taken to reach the temperature (at $28^{\circ} \mathrm{C}$ ) at which the cell changes from the white state to the completely dark state as shown in Fig. 2(a) and 2(c). As the temperature of heating effects with respect to applied voltage to the cell is increased, turn on time decreased. When supplying a power of $1 \mathrm{~W}$ $\left(72^{\circ} \mathrm{C}\right)$, the cell changed from the black state to the white state within $1 \mathrm{~s}$, while turn off time showed about $7.5 \mathrm{~s}$ at room temperature. The time taken to "turn on" or "turn off" depends on the type of thermochromic pigment and substrate and so on. The time that heat is dissipated from the display cell was measured in the range from 1 to $8 \mathrm{~s}$ at $25^{\circ} \mathrm{C}$. For the display cell the black state was observed below about $2 \mathrm{~V}$, whereas the brightness of the RTD cell was turned from a black state to a white state within a few seconds by applying a voltage above $4 \mathrm{~V}$. The pixel images in Fig. 2(c) show that the temperature increased 
homogeneously between the electrodes with increasing applied voltage. This means that various gray levels with continuous brightness according to temperature can be obtained in a RTD cell.

The spectral reflectance of the thermochromic display cell was measured as a function of the temperature to confirm the various gray levels shown in Fig. 2. Fig. 3
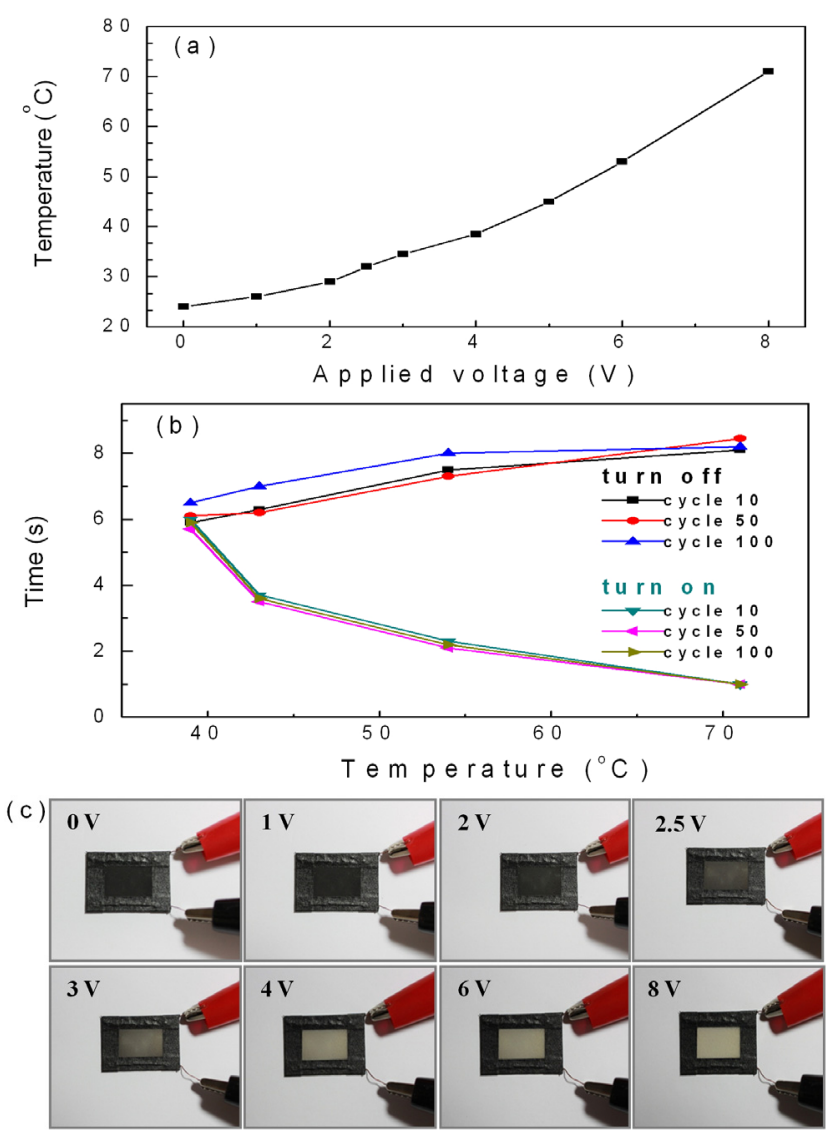

FIG. 2. Photo images of the thermochromic display cell according to the applied voltage, from 0 to $8 \mathrm{~V}$.

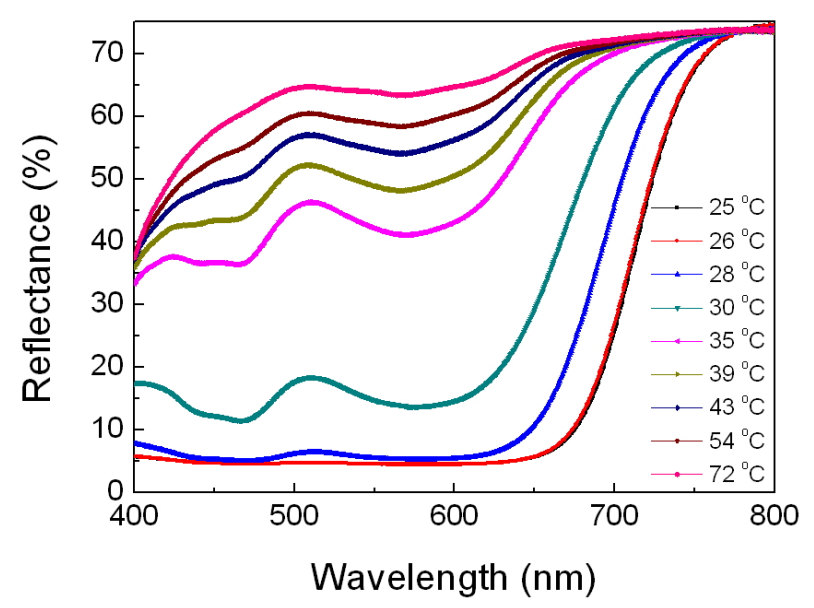

FIG. 3. Reflectance spectra of monochromatic thermochromic pigment according to the temperature. shows changes in the reflectance spectra with various temperatures by controlling supplied power to the RTD cell. With increasing temperature, the white reflectance was increased by approximately $65 \%$ over the entire visible range. Here, the dimension of the cell is $1.5 \times 2.5 \mathrm{~cm}^{2}$, and the white maximum reflectance showed at $72^{\circ} \mathrm{C}$, which corresponded to about $1 \mathrm{~W}$ of supplied power. This shows that the reflectance can be varied by controlling temperature of the cell according to the intensity of the supplied power to the RTD cell. The thermochromic pigment showed a clearly distinctive spectrum, which is a crucial factor in the activation of a reflective fine gray level as a function of temperature.

The optical and mechanical cell stability of flexible thermochromic display cells were examined by mechanical distortion to determine the potential of the thermochromic cell for flexible information poster display applications. The display device was composed of a flexible PEN film and a monochromatic pigment coated on the patterned ITO-sputtered PEN substrate using a spray method and dried at room temperature for approximately 10 minutes.

Figure 4 shows photo images of the thermochromic display cell with the logo, "RTD", under no applied voltage and under applied voltage of $8 \mathrm{~V}$ in the bent state. Even in a highly bent state, the spatial uniformity of light modulation

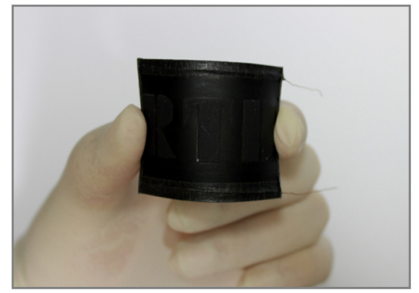

(a)

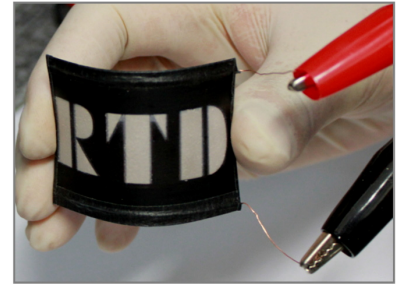

(b)

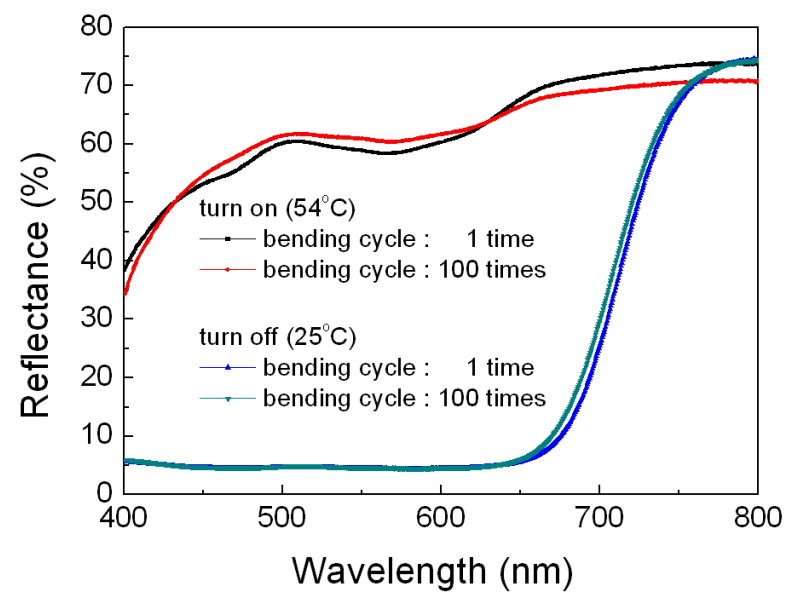

(c)

FIG. 4. Optical images of thermochromic display cell with the "RTD" logo under mechanical bending: (a) before display activation, (b) at the applied voltage of $8 \mathrm{~V}$, (c) Reflectance spectra at room temperature and $54^{\circ} \mathrm{C}$ of thermochromic display cell after repetitive bending stress. 
could be observed without damage. For simplicity, this display cell was fabricated by spraying the thermochromic pigment using the patterned logo mask of RTD shape on the ITO-heater.

The reflectance of the cell measured at room temperature $\left(25^{\circ} \mathrm{C}\right)$ and $54^{\circ} \mathrm{C}$ was almost the same without any significant degradation after repetitive bending stress of 100 times as shown in Fig. 4(c). When the applied voltage was above $4 \mathrm{~V}$, the logo image appeared within a few seconds. Furthermore, the thin-film thermochromic display could be adapted easily to a range of application environments due to the polyethylene naphthalate (PEN) matrix.

Consequently, the proposed thermochromic display cell shows great potential in various thermally comfortable poster information reflective display applications where low cost is needed, in spite of its slow response time.

\section{CONCLUSION}

This paper presented a reflective type flexible thermochromic display comprised of ITO-sputtered polyethylene naphthlate (PEN) film and thermochromic pigment. The thermochromic cell is fabricated using a spray method which may be a very simple and cost effective fabrication process. The cell exhibited excellent thermo-optical performance and stability, even in a highly distorted state. Our reflective thermochromic cell is expected to be used in various information displays where cost efficient, lightweight and ease of use are required. In particular, it appears useful for thermally comfortable outdoor and/or indoor reflective display types, and can be used for low-end e-paper and information applications.

\section{ACKNOWLEDGMENT}

This research was supported by the 2012 Yeungnam University research grant and the Human Resources Development Program of Korea Institute of Energy Technology Evaluation and Planning Grant (No. 20104010100580) funded by the Korea government Ministry of Knowledge Economy.

\section{REFERENCES}

1. D.-W. Kim, C.-J. Yu, Y.-W. Lim, J.-H. Na, and S.-D. Lee, "Mechanical stability of a flexible ferroelectric liquid crystal display with a periodic array of columnar spacers," Appl. Phys. Lett. 87, 051917-1 051917-3 (2005).

2. H. Sato, H. Fujikae, Y. Iino, M. Kawakita, and H. Kikuchi, "Flexible grayscale ferroelectric liquid crystal device containing polymer walls and networks," Jpn. J. Appl. Phys. 41, 5302-5306 (2002).

3. H. Sato, H. Fujikae, H. Kikuchi, and T. Kurita, "Fluorinated polymer alignment layers formed at low temperature for plastic-substrate-based liquid crystal devices,” Jpn. J. Appl. Phys. 40, L53-L55 (2001).

4. A. Henzen, N. Ailenei, F. V. Reeth, G. Vansichem, R. W. Zehner, and K. Amundson, "An electronic ink low latency drawing tablet," SID Int. Symp. Digest Tech. Papers 35, 1070-1073 (2004).

5. L. Liu, S. Pen, W. Wen, and P. Sheng, "Paperlike thermochromic display," Appl. Phys. Lett. 90, 213508-1 213508-3 (2007).

6. Y. Noguchi, T. Sekitani, and T. Someya, "Organic-transistorbased flexible pressure sensors using ink-jet-printed electrodes and gate dielectric layers," Appl. Phys. Lett. 89, 253507-1 253507-3 (2006).

7. H. A. Seeboth, J. Kriwanek, and R. Vetter, "Novel chromogenic polymer gel networks for hybrid transparency and color control with temperature," Adv. Mater. (Weinheim, Ger.) 12, 1424-1426 (2000).

8. O. Yarimaga, M. Im, B. Gu, T. W. Kim, Y. K. Jung, H. G. Park, Y.-K. Choi, "A thermally actuated organic display device using thermo-chromatic polymer composite film with self-aligned patterns," in Proc. IEEE MEMS Technical Digest (Tucson, Arizona, USA, 2008), pp. 750-753.

9. M. Seredyuk, A. B. Gaspar, V. Ksenofontov, S. Reiman, Y. Galyametdinov, W. Haase, and R. Vetter, and P. Gutlich, "Room temperature operational thermochromic liquid crystals," Chem. Mater. 18, 2513 (2006).

10. A. Mills and A. Lepre, "Development of novel thermochromic plastic films for optical temperature sensing," The Analyst 124, 685 (1999).

11. M. G. Baron, M. Elie, M. G. Baron, and M. Elie, "Temperature sensing using reversible thermochromic polymeric films," Sens. Actuators B Chem. 90, 271-275 (2003).

12. http://www.hwsand.com/category/141.aspx.

13. D. C. Maclaren and M. A. White, "Design rules for reversible thermochromic mixtures," J. Mater. Chem. 40, 669-676 (2005).

14. G. Shimizu, Shiga, and Y. Hayasshi, "Thermochromic composition," U.S. Patent, US4717710 (5, January, 1998). 